\title{
Connection of water permeability with a number of physical properties of polymers
}

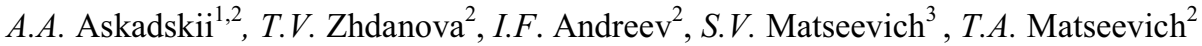 \\ ${ }^{1}$ A. N. Nesmeyanov Institute of Organoelement compounds Russian Academy of Sciences, \\ Department of high-molecular compounds, Moscow, 119991, Russia \\ ${ }^{2}$ Moscow State University of Civil Engineering, Yaroslavskoe shosse, 26, Moscow, 129337, Russia \\ ${ }^{3}$ Lomonosov Moscow State Universuty, Physical faculty, GSP-1, Leninskie Gory, Moscow, 119991, \\ Russia
}

\begin{abstract}
Currently, methods for predicting the properties of polymers are very popular, since they simplify the work of synthetic chemists. Instead of lengthy and time-consuming experiments, many properties of polymers can be predicted in advance based on their chemical structure. Naturally, such tasks must be computerized so that the properties are predicted after the chemical structure of the repeating polymer unit is displayed on the display screen. This is the so-called direct task. The inverse problem is more complex and interesting. It consists in entering the intervals of the desired characteristics into the computer. Then computer synthesis of polymers possessing these characteristics are realized. The work consists in writing a computer program that allows the computer synthesis of polymers of different classes with specified intervals of water permeability. These classes include polyurethanes, polysulfones, polysulfides, polyethers and polyesters, polyamides, polyketones and polyethyrketones, polycarbonates, polyolefins, vinyl polymers, polystyrene, acrylic and methacrylic polymers. On the basis of this program, water permeability compatibility diagrams are constructed with various physical characteristics of polymers - glass transition temperature, temperature of the onset of intensive thermal degradation, cohesion energy, density, solubility parameter (Hildebrand parameter).
\end{abstract}

\section{Introduction}

Materials used in the construction industry often require polymers that possess a combination of a number of properties. For example, for exterior finishing materials, a combination of low water permeability and high glass transition temperature (softening) is required. This is necessary so that the material does not pass into a rubbery state and changes its shape when heated, but remains solid while maintaining its shape. To do this, you can use the "compatibility diagrams", the construction of which is described in the monographs [1-3]. A schematic representation of the compatibility diagram is shown in Figure 1. 


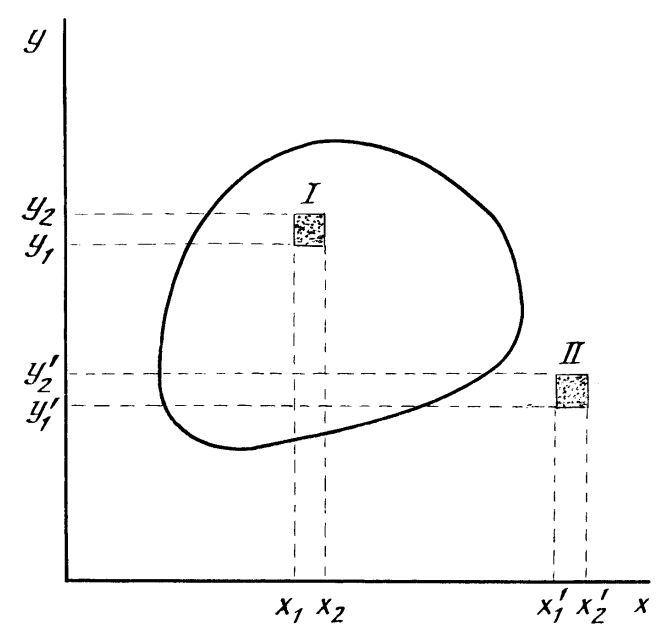

Fig. 1. Schematic representation of the compatibility diagram

The compatibility diagram contains a very large (many thousands) number of points inside some area that is outlined. If there are points inside this region, then the existence of polymers with coordinates $X_{1}$ and $X_{2}, Y_{1}$ and $Y_{2}$ is possible (case I). If the points with coordinates $X_{1}$ and $X_{2}, Y_{1}$ and $Y_{2}$ are outside this region, then polymers with the given values $Y_{1}^{\prime}$ and $Y_{2}$ do not exist (case II).

As an example, Figure 2 shows the compatibility diagram of the glass transition temperature $T_{\mathrm{g}}$ and the solubility parameter $\delta$ (Hildebrand parameter). This parameter is important for predicting the solubility of the polymer in a given solvent.

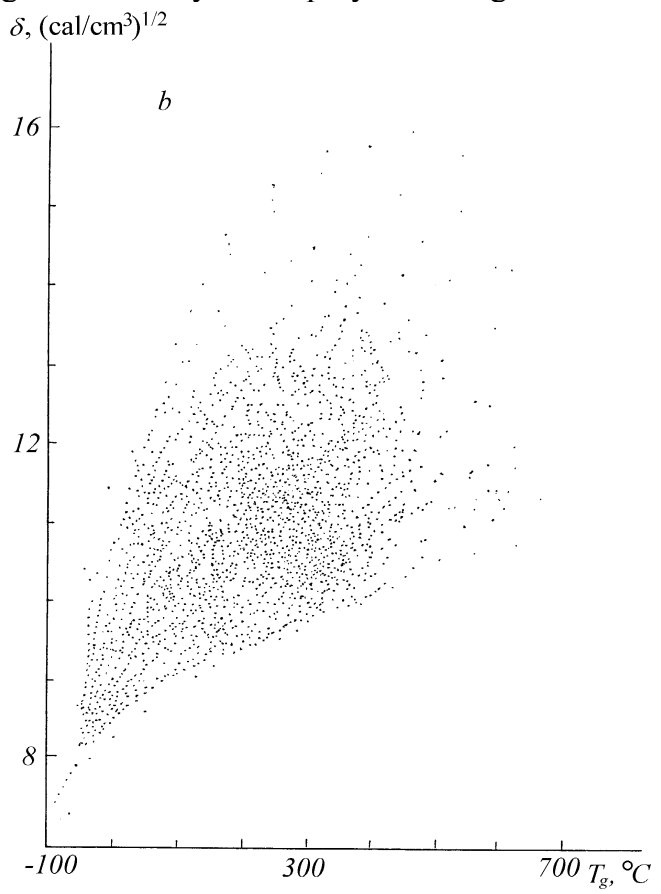

Fig. 2. Compatibility diagram of $\delta$ and $T_{\mathrm{g}}$ (see text) 
Such diagrams allow us to predict the possibility of preparation polymers that possess the desired combination of two properties. When using computer analysis of the construction of such diagrams using the program "Cascade" (INEOS RAS), the polymer compatibility areas will consist of the parameters of the properties of a huge number of polymers.

One of the most common polymers for the manufacture of building materials is polyvinyl chloride (PVC). Therefore, much attention is paid to the study of water permeability through polymer membranes for materials based on this polymer. The permeability of water vapor through the films of not only PVC itself, but also its copolymers with perchlorovinyl, vinyl acetate and ethylene, was studied in [4]. A nonlinear dependence of the permeability on the film thickness is found. Dependencies of this kind are also found for membranes based on vulcanized rubber. These dependencies are described using the equation proposed in [5], based on theoretical developments [6-7]. The barrier properties of polysulfone-based membranes were studied in [8-11].

In connection with the use of polymer blends for the production of building materials, we will consider several theoretical positions related to the compatibility of polymers. The papers [12-14] are devoted to the analysis of the thermodynamics of polymer compatibility. On this basis, methods for predicting compatibility are also proposed. The methods use the PRISM theory, which is described in detail in [15]. Another model called LCT operates on cluster theory [16-17]. There is also the modified model [18].

Let's turn to the works that are devoted to mixtures of specific polymers. In [19], the blend of polypropylene with low-pressure polyethylene is considered, and in [20] - the blends of the same polymer with polyamide-11 and EPDM copolymer. There are also data on blends of polyamide-66 with polyethylene terephthalate [21]. During shear deformation, the structure of blends of polystyrene with methyl methacrylate oligomers, as well as mixtures of polypropylene with a copolymer of polypropylene with ethylene, changes [2223]. Having a related component improves compatibility.

\section{Methods}

The formulas used to combine the parameters of two properties are given in the monograph [24]. Our work is devoted to constructing compatibility diagrams of the water permeability of polymers with such physical characteristics as the glass transition temperature, the temperature of the onset of intensive degradation, and the cohesion energy. Once again, water permeability is important for polymer materials used in the construction industry for outdoor use. The glass transition temperature allows you to determine whether the material is in a glassy state, i.e., whether it is high-modulus. The cohesion energy is a fundamental factor for the dependence of water permeability on the chemical structure of the polymer. The temperature of the onset of intensive thermal degradation allows us to characterize the temperature of foaming of the polymer material, which leads to a decrease in flammability. The description of the permeability of $P$ polymers was carried out according to the general equation (1)

$$
P=P_{0} e^{-\frac{\Delta E}{R T}}
$$

where $P_{0}$ is the constant, $\Delta E$ is the activation energy of the permeability process, $R$ is the universal gas constant, and $T$ is the absolute temperature.

The value of $\Delta E$ was described by the ratio [25-26] 


$$
\Delta E=\frac{\sum_{i} \Delta E_{i}^{\times *}}{N_{A} \sum_{i} \Delta V_{i}}
$$

where $N_{A}$ is the Avogadro number, $\sum_{i} \Delta V_{i}$ is the van der Waals volume of the repeating polymer unit, $\sum_{i} \Delta E_{i}^{* *}$ is the energy of the intermolecular interaction, which consists of the interaction energies of each atom and specific atomic groups that cause dipole-dipole interactions or hydrogen bonds.

Then

$$
\ln P=\ln P_{0}-\frac{\sum_{i} \Delta E_{i}^{* *}}{N_{A} R T \sum_{i} \Delta V_{i}}
$$

After a small transformation, we have:

$$
\frac{\sum_{i} \Delta E_{i}^{* *}}{R T}-\left(N_{A} \sum_{i} \Delta V_{i}\right) \ln P_{0}=-\left(N_{A} \sum_{i} \Delta V_{i}\right) \ln P
$$

Atomic constants and parameters that characterize the energy of strong intermolecular interactions are available in [25-26]. The value of $\ln P_{0}=3.002$ (barrer).

The glass transition temperature was described by the equation

$$
T_{g}=\frac{\sum_{i} \Delta V_{i}}{\left(\sum_{i} a_{i} \Delta V_{i}+\sum_{j} b_{j}\right)_{l}+\left(\sum_{i} K_{i} \Delta V_{i}\right)_{c r, p}}
$$

$\sum_{\text {where }} \Delta V_{i}$ is the van der Waals volume of a repeating fragment of a polymer network; $\left(\sum_{i} a_{i} \Delta V_{i}+\sum_{j} b_{j}\right)_{l}$

connecting cross-linked points; $\left(\sum_{i} K_{i} \Delta V_{i}\right)_{c r . p .}$ is a set of atomic constants for a crosslinked point (for the physical meaning of the parameters $a_{i}, b_{j}$ and $K_{i}$, see [27-28]).

The temperature of the onset of intensive thermal degradation is determined from the ratio

$$
T_{d}=\frac{\sum_{i} \Delta V_{i}}{\sum_{i} K_{i} \Delta V_{i}}
$$


where $K_{i}$ are the atomic constants associated with the parameters of the Morse potential; $K_{i}=\frac{63}{2} \frac{R}{\left(1 d_{0} E\right)_{i}}$; a and $d_{0}$ are the parameters of the Morse potential, $E$ is the energy of the chemical bond.

For copolymers the ratio (7) is used

$$
T_{g}=\frac{\sum_{k=1}^{k=n} \alpha_{k}\left(\sum_{i} \Delta V_{i}\right)_{k}}{\sum_{k=1}^{k=n} \alpha_{k} \frac{\left(\sum_{i} \Delta V_{i}\right)_{k}}{T_{g, k}}+0.03 \sum_{k=1}^{k=n} \alpha_{k}\left(1-\alpha_{k}\right)},
$$

where $\alpha_{k}$ is the molar fraction of the $k$-th component, $\mathrm{n}$ is the number of components, $T_{g, k}$ is the glass transition temperature of the $k$-th component, $\sum_{i} \Delta V_{i}$ is the van der Waals volume of the $k$-th component.

The cohesion energy $\Delta E^{*}$ is calculated by the ratio

$$
\Delta E^{*}=\sum_{i} \Delta E_{i}^{*}
$$

where $\Delta E_{i}^{*}$ is the contribution of each atom and the type of intermolecular interaction to $\sum_{i} \Delta E_{i}^{*}$

The cohesion energy of a repeating polymer unit is described by the equation [25-26]

$$
\sum_{i} \Delta E_{i}^{*}=\delta^{2} N_{A} \sum_{i} \Delta V_{i}
$$

where $\delta$ is the solubility parameter (Hildebrand parameter).

The density of polymers $\mathrm{p}$ is described by the ratio:

$$
\rho=\frac{M k}{N_{A} \sum_{i} \Delta V_{i}}
$$

where $M$ is the molecular weight of the repeating unit, $k$ is the molecular packing coefficient (averaged value $k=0.681$ ).

We obtain the relations connecting water permeability with the other characteristics considered above. This can be done, since all the equations include the van der Waals volume of the repeating polymer unit. The water permeability and glass transition temperature of linear polymers are related by the ratio:

$$
\ln P=3.002-\frac{\sum_{i} \Delta E_{i}^{8 \varepsilon}}{N_{A} R T \cdot T_{g}\left(a_{i} \Delta V_{i}+\sum_{j} b_{j}\right)} .
$$


Water permeability and the temperature of the onset of intensive degradation are related by the ratio:

$$
\ln P=3.002-\frac{\sum_{i} \Delta E_{i}^{8 *}}{N_{A} R T \cdot T_{d} \sum_{i} K_{i} \Delta V_{i}}
$$

Water permeability is related to density by the ratio:

$$
\ln P=3.002-\frac{\rho \sum_{i} \Delta E_{i}^{* *}}{R T \cdot M k} .
$$

Water permeability is related to the cohesion energy by the ratio:

$$
\ln P=3.002-\frac{\delta^{2} \sum_{i} \Delta E_{i}^{* *}}{R T \sum_{i} \Delta E_{i}^{*}}
$$

\section{Results}

The existing computer program Cascade, developed at INEOS RAS, allows for the computer synthesis of polymers with a given water permeability. For polymer materials for construction purposes, polymers with very low water permeability are of interest, if they are designed to work in outdoor conditions of a humid environment. In some other cases, materials with high water permeability are required. In this paper, a real computer program is written that allows you to construct polymer compatibility diagrams in automatic mode.

Table 1 shows, as an example, the structures of polycarbonates with low water permeability.

Table 1. Low permeability of polycarbonates (from 0 to 70 barrers)

$\begin{array}{lllllll}\text { № } & \text { Chemical formula } & P, & T_{g}, & T_{d,} & E^{*}, & \rho, \\ & & \text { barrer } & \mathrm{K} & \mathrm{K} & \mathrm{J} / \mathrm{mol} & \mathrm{g} / \mathrm{cm}^{3} \\ 1 & \text {-OCOO-mC6H4-C(Cl)(C6H5)-mC6H4- } & 66.2 & 419 & 654 & 106000 & 1.29 \\ 2 & \text {-OCOO-mC6H4-C(Cl)(C6H5)-pC6H4- } & 66.2 & 445 & 654 & 106000 & 1.29 \\ 3 & \text {-OCOO-mC6H4-CH(C6H32,4Cl2)-mC6H4- } & 41.5 & 401 & 626 & 114000 & 1.36 \\ 4 & \text {-OCOO-mC6H4-CH(C6H32,4Cl2)-pC6H4- } & 41.5 & 424 & 626 & 114000 & 1.36 \\ 5 & \text {-OCOO-mC6H4-CH(C6H32,4Cl2)-pC6F4- } & 65.7 & 434 & 639 & 114000 & 1.53 \\ 6 & \text {-OCOO-mC6H4-CH(C6H32,5Cl2)-mC6H4- } & 41.5 & 401 & 626 & 114000 & 1.36 \\ 7 & \text {-OCOO-mC6H4-CH(C6H32,5Cl2)-pC6H4- } & 41.5 & 424 & 626 & 114000 & 1.36 \\ 8 & \text {-OCOO-mC6H4-CH(C6H32,5Cl2)-pC6F4- } & 65.7 & 434 & 639 & 114000 & 1.53 \\ 9 & \text {-OCOO-mC6H4-CH(C6H32,6Cl2)-mC6H4- } & 41.5 & 401 & 626 & 114000 & 1.36 \\ 10 & \text {-OCOO-mC6H4-CH(C6H32,6Cl2)-pC6H4- } & 41.5 & 424 & 626 & 114000 & 1.36 \\ 11 & \text {-OCOO-mC6H4-CH(C6H32,6Cl2)-pC6F4- } & 65.7 & 434 & 639 & 114000 & 1.53 \\ 12 & \text {-OCOO-mC6H4-CH(C6H42Cl)-mC6H4- } & 67.2 & 403 & 654 & 106000 & 1.29 \\ 13 & \text {-OCOO-mC6H4-CH(C6H42Cl)-pC6H4- } & 67.2 & 427 & 654 & 106000 & 1.29 \\ 14 & \text {-OCOO-mC6H4-CH(C6H43Cl)-mC6H4- } & 67.2 & 403 & 654 & 106000 & 1.29 \\ 15 & \text {-OCOO-mC6H4-CH(C6H43Cl)-pC6H4- } & 67.2 & 427 & 654 & 106000 & 1.29 \\ 16 & \text {-OCOO-mC6H4-CH(C6H44Cl)-mC6H4- } & 67.2 & 403 & 654 & 106000 & 1.29 \\ 17 & \text {-OCOO-mC6H4-CH(C6H44Cl)-pC6H4- } & 67.2 & 427 & 654 & 106000 & 1.29 \\ 18 & \text {-OCOO-mC6H4-Fl-mC6H4- } & 60.0 & 468 & 656 & 123000 & 1.24 \\ 19 & \text {-OCOO-mC6H4-Fl-pC6H4- } & 60.0 & 497 & 656 & 123000 & 1.24 \\ 20 & \text {-OCOO-pC6H4-C(Cl)(C6H5)-mC6H4- } & 66.2 & 445 & 654 & 106000 & 1.29\end{array}$




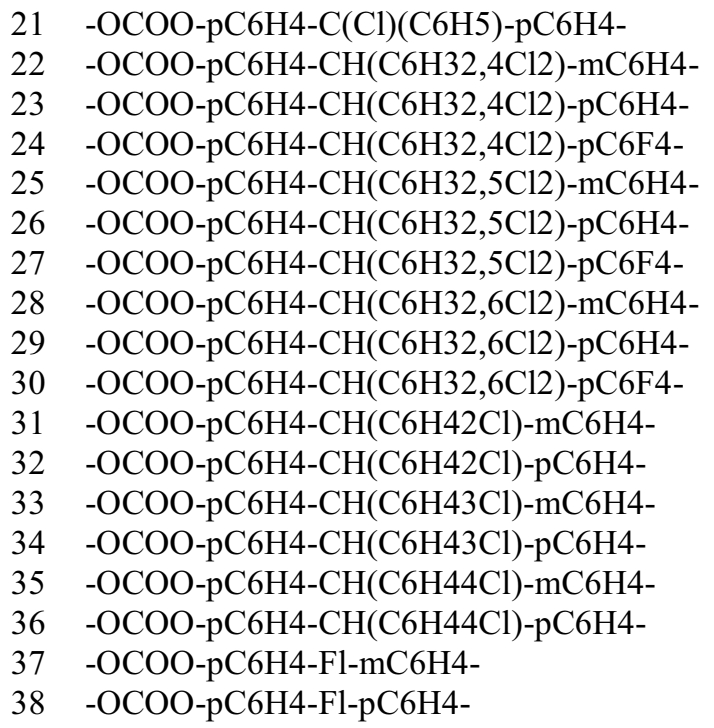

$\begin{array}{lllll}66.2 & 475 & 654 & 106000 & 1.29 \\ 41.5 & 424 & 626 & 114000 & 1.36 \\ 41.5 & 450 & 626 & 114000 & 1.36 \\ 65.7 & 459 & 639 & 114000 & 1.53 \\ 41.5 & 424 & 626 & 114000 & 1.36 \\ 41.5 & 450 & 639 & 114000 & 1.53 \\ 65.7 & 459 & 639 & 114000 & 1.53 \\ 41.5 & 424 & 626 & 114000 & 1.36 \\ 41.5 & 450 & 639 & 114000 & 1.53 \\ 65.7 & 459 & 639 & 114000 & 1.53 \\ 67.2 & 427 & 654 & 106000 & 1.29 \\ 67.2 & 454 & 654 & 106000 & 1.29 \\ 67.2 & 427 & 654 & 106000 & 1.29 \\ 67.2 & 454 & 654 & 106000 & 1.29 \\ 67.2 & 427 & 654 & 106000 & 1.29 \\ 67.2 & 454 & 654 & 106000 & 1.29 \\ 60.0 & 497 & 656 & 123000 & 1.24 \\ 60.0 & 528 & 656 & 123000 & 1.24\end{array}$

Figure 3 shows the compatibility diagrams of water permeability with a number of properties of polyamides. The number of base fragments is 5 .

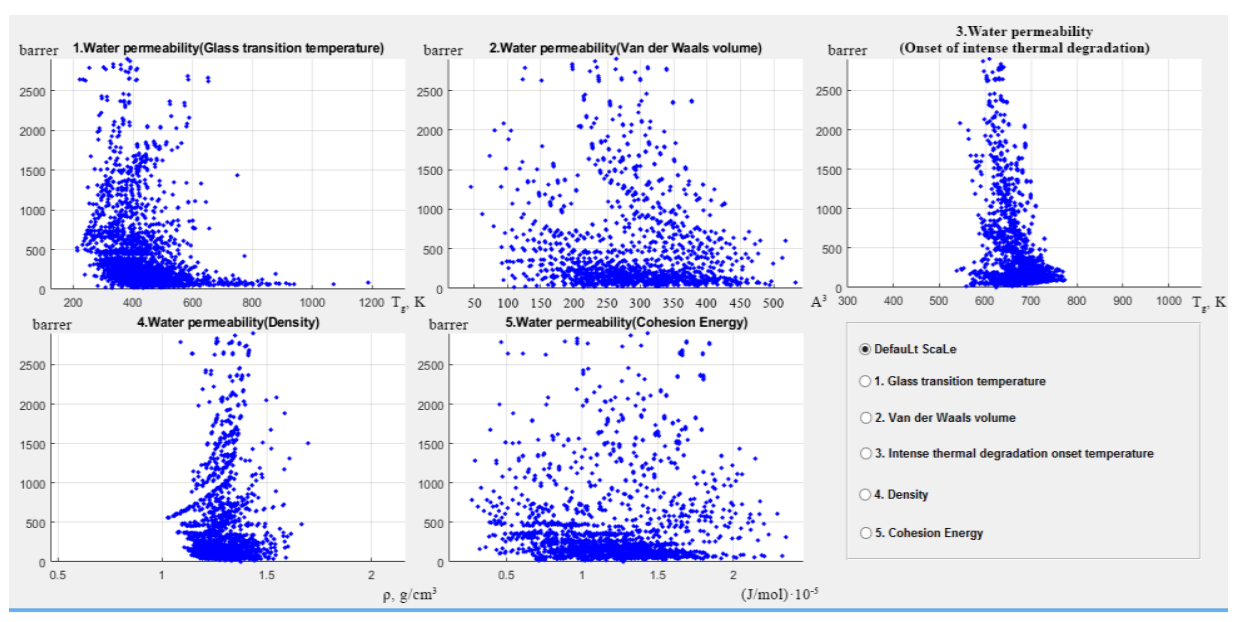

Fig. 3. Diagrams of water permeability with a number of properties of polyamides

These diagrams allow you to select polymers that meet the specified values of water permeability, density, cohesion energy, transition temperature, and the temperature of the onset of intensive thermal degradation.

It is of interest to estimate the number of structures of repeating units that lead to different intervals of water permeability. To calculate the number of structures, five water permeability intervals were selected, which are shown in Table 2 for each polymer. These intervals for each polymer are different based on the maximum water permeability value for each class. Table 2 shows that the largest number of structures of repeating polymer units falls on the lowest range of water permeability. 
Table 2. The number of polymer structures when specifying different water permeability intervals

\begin{tabular}{|c|c|c|c|c|c|}
\hline Class of & \multicolumn{5}{|c|}{ The water permeability intervals } \\
\hline \multirow[t]{3}{*}{$\begin{array}{c}\text { Polyolefins, } \\
\text { vinyl polymers }\end{array}$} & $0-500$ & $500-1000$ & $\begin{array}{l}1000- \\
1500\end{array}$ & $\begin{array}{l}1500- \\
2000\end{array}$ & $2000-2570$ \\
\hline & \multicolumn{5}{|c|}{ Quantity of structures } \\
\hline & 12 & 5 & 3 & 2 & 2 \\
\hline \multirow{4}{*}{ Polystyrenes } & \multicolumn{5}{|c|}{ The water permeability intervals } \\
\hline & $0-30$ & $30-60$ & $60-90$ & $90-120$ & $120-150$ \\
\hline & \multicolumn{5}{|c|}{ Quantity of structures } \\
\hline & 28 & 7 & 14 & 1 & 3 \\
\hline \multirow{4}{*}{$\begin{array}{l}\text { Acrylic and } \\
\text { methacrylic } \\
\text { polymers }\end{array}$} & \multicolumn{5}{|c|}{ The water permeability intervals } \\
\hline & $0-2000$ & $\begin{array}{c}2000- \\
4000\end{array}$ & $\begin{array}{c}4000- \\
6000\end{array}$ & $\begin{array}{l}6000- \\
8000\end{array}$ & $8000-10085$ \\
\hline & \multicolumn{5}{|c|}{ Quantity of structures } \\
\hline & 42 & 0 & 1 & 2 & 0 \\
\hline \multirow{4}{*}{$\begin{array}{c}\text { Polyketone, } \\
\text { polyetherketone }\end{array}$} & \multicolumn{5}{|c|}{ The water permeability intervals } \\
\hline & $0-5100$ & $\begin{array}{l}5100- \\
10200\end{array}$ & $\begin{array}{l}10200- \\
15300\end{array}$ & $\begin{array}{l}15300- \\
20400\end{array}$ & $20400-25500$ \\
\hline & \multicolumn{5}{|c|}{ Quantity of structures } \\
\hline & 23296 & 1552 & 372 & 200 & 80 \\
\hline \multirow[t]{4}{*}{ Polyethers } & \multicolumn{5}{|c|}{ The water permeability intervals } \\
\hline & $0-5600$ & $\begin{array}{l}5600- \\
11200\end{array}$ & $\begin{array}{c}11200- \\
16800\end{array}$ & $\begin{array}{l}16800- \\
22400\end{array}$ & $22400-28000$ \\
\hline & \multicolumn{5}{|c|}{ Quantity of structures } \\
\hline & 26568 & 940 & 256 & 114 & 22 \\
\hline \multirow[t]{4}{*}{ Polyesters } & \multicolumn{5}{|c|}{ The water permeability intervals } \\
\hline & $0-6000$ & $\begin{array}{l}6000- \\
12000\end{array}$ & $\begin{array}{l}12000- \\
18000\end{array}$ & $\begin{array}{l}18000- \\
24000\end{array}$ & $24000-30000$ \\
\hline & \multicolumn{5}{|c|}{ Quantity of structures } \\
\hline & 24596 & 3368 & 979 & 476 & 81 \\
\hline \multirow[t]{4}{*}{ Polyamides } & \multicolumn{5}{|c|}{ The water permeability intervals } \\
\hline & $\begin{array}{c}0- \\
154000\end{array}$ & $\begin{array}{l}154000- \\
308000\end{array}$ & $\begin{array}{c}308000- \\
462000\end{array}$ & $\begin{array}{c}462000- \\
616000\end{array}$ & $616000-770000$ \\
\hline & \multicolumn{5}{|c|}{ Quantity of structures } \\
\hline & 769466 & 399 & 61 & 47 & 27 \\
\hline \multirow[t]{4}{*}{ Polysulphides } & \multicolumn{5}{|c|}{ The water permeability intervals } \\
\hline & $\begin{array}{c}0- \\
150000 \\
\end{array}$ & $\begin{array}{l}150000- \\
300000\end{array}$ & $\begin{array}{c}300000- \\
450000\end{array}$ & $\begin{array}{c}450000- \\
600000\end{array}$ & $600000-750000$ \\
\hline & \multicolumn{5}{|c|}{ Quantity of structures } \\
\hline & 747552 & 270 & 80 & 84 & 14 \\
\hline \multirow[t]{4}{*}{ Polysulphones } & \multicolumn{5}{|c|}{ The water permeability intervals } \\
\hline & $\begin{array}{c}0- \\
194000\end{array}$ & $\begin{array}{l}194000- \\
388000\end{array}$ & $\begin{array}{c}388000- \\
582000\end{array}$ & $\begin{array}{c}582000- \\
776000\end{array}$ & $776000-970000$ \\
\hline & \multicolumn{5}{|c|}{ Quantity of structures } \\
\hline & 969360 & 432 & 124 & 66 & 28 \\
\hline Polyurethanes & & The & ater perm & ility inter & \\
\hline & $\begin{array}{c}0- \\
104000\end{array}$ & $\begin{array}{l}104000- \\
208000\end{array}$ & $\begin{array}{l}208000- \\
312000\end{array}$ & $\begin{array}{c}312000- \\
416000\end{array}$ & $416000-520000$ \\
\hline
\end{tabular}




\begin{tabular}{|c|c|c|c|c|c|}
\hline \multirow{2}{*}{} & \multicolumn{5}{|c|}{ Quantity of structures } \\
\cline { 2 - 6 } & 519868 & 94 & 22 & 14 & 2 \\
\hline
\end{tabular}

\section{Discussion}

A computer program is written that allows you to build compatibility diagrams of water permeability with the physical characteristics listed above. With the help of this program, in this paper, as an example, compatibility diagrams of water permeability with a number of characteristics for polyamides are constructed. We also found the number of chemical structures of different classes that fall into the water permeability ranges from very small to ultra-high.

\section{Conclusions}

As a result of this work, the computer program was written that allows us to design compatibility diagrams of various physical characteristics with the water permeability of polymers. It is found that from a number of polymers (polyurethanes, polysulfones, polysulfides, simple and complex polyesters, polyamides, polyketones and polyethyrketones), a huge number of structures with relatively low water permeability can be selected. The choice of structures with high water permeability is significantly limited. This choice is typical for polyolefins, vinyl polymers, acrylic and methacrylic polymers. The reason, as noted above, is that the repeating units of polymers of this group are synthesized from two basic fragments, and for the remaining polymers - from six base fragments. The given computer program can be used by specialists in the development of polymer materials for the construction industry.

This work was carried out with the financial support of the Ministry of science and higher education of the Russian Federation (project "Theoretical and experimental design of new composite materials for ensuring safety in the operation of buildings and structures in conditions of technogenic and biogenic threats" no. FSWG-2020-0007 MGSU, and subject of the state task of INEOS RAS no. 0085-2019-0004).

The following works were performed at MGSU: writing a computer program, performing calculations, making drawings and tables; the following works were performed at INEOS RAS: select classes of polymers for making diagrams of compatibility, calculation of permeability.

\section{References}

1. A.A. Askadskii, Computational Materials Science of Polymers, Cambridge International Science Publishing, Cambridge, 695 pp (2003)

2. A.A. Askadskij, V.I. Kondrashchenko, Komp'yuternoe materialovedenie polimerov. T.1. Atomno-molekulyarnyj uroven'. M.: Nauchnyj Mir, 543 s, (1999)

3. A.A. Askadskii, T.A.Matseevich, M.N. Popova, Vtorichnye polimernye materialy. Mekhanicheskie i bar'ernye svojstva, plastifikaciya, smesi i nanokompozity. M.: Izd-vo ASV, 490 s (2017)

4. M. Paul, H.B. Park, B.D. Freeman, A. Roy, J.E. McGrath, J.S. Riffle // Polymer, 49, p. 2243-2252 (2008)

5. J.E. McGrath, H.B. Park, B.D. Freeman, Chlorine Resistant Desalination Membranes Based on Directly Sulfonated Poly(Arylene Ether Sulfone) Copolymers. Pat. 11/655319 USA (2007). 
6. H.B. Park, B.D. Freeman, Z.-B. Zhang, M. Sankir, J.E. McGrath, Highly ChlorineTolerant Polymers for Desalination. Angewandte Chemie, 47 (32), pp. 6019-6024 (2008)

7. W. Xie, H.B. Park, J. Cook, C.H. Lee, G. Byun, B.D. Freeman, J.E. McGrath // Water Science and Technology, 61 (3). P. 619-624 (2010)

8. M. Paul, H.B. Park, B.D. Freeman, A. Roy, J.E. McGrath, J.S. Riffle, Synthesis and crosslinking of partially disulfonated polyether sulfone random copolymers as candidates for chlorine resistant reverse osmosis membranes. Polymer, 49, p. 2243 $2252(2008)$

9. J.E. McGrath, H.B. Park, B.D. Freeman, Chlorine Resistant Desalination Membranes Based on Directly Sulfonated Poly(Arylene Ether Sulfone) Copolymers. Pat. 11/655319 USA, (2007)

10. H.B. Park, B.D. Freeman, Z.-B. Zhang, M. Sankir, J.E. McGrath, Highly ChlorineTolerant Polymers for Desalination. Angewandte Chemie, 47 (32), pp. 6019-6024 (2008)

11. W. Xie, H.B. Park, J. Cook, C.H. Lee, G. Byun, B.D. Freeman, J.E McGrath // Water Science and Technology, 61 (3). P. 619-624 (2010)

12. Polimernye smesi. Tom 1: Sistematika. Pod redakciej D.R.Pola i K.B. Baknella. Perevod s anglijskogo pod redakciej prof. V.N. Kulezneva. Sankt-Peterburg, Izd-vo NOT, 618 str (2009)

13. Edited by D.R. Paul and C.B. Bucknall. John Willey and Sons, Polymer Blends. Vol. 1: Formulation, Inc. New York, 600 pp (2000)

14. V.N. Kuleznev, Smesi polimerov (struktura i svojstva). M.: Himiya, (1980)

15. V.N. Kuleznev, Smesi i splavy polimerov. Sankt-Peterburg, Izd-vo NOT, 216 str (2013)

16. K.S. Schweizer, J.G. Curro // Adv. Chem. Phys. 98, 1-142 CXVIII, 1 (1997)

17. K.F. Freed, J. Dudowicz // Modern Trends in Polymer Science, 3, 248 pp (1995)

18. K.F. Freed, J. Dudowicz, K.W. Forman // J. Chem. Phys, 108, 7881 (1998.)

19. A.M. Kochnev, A.E. Zaikin, S.S. Galibeev, V.P. Arhireev, Fizikohimiya polimerov. Kazan': Izd-vo «Fen», $512 \operatorname{str}(2003)$

20. Y. Wang, V. Na, Q. Fu, Y. Men //Polymer, 45. N. 1. P. 207 (2004)

21. B.B. Wang, L.X. Wei, G.S. Hu // J. of Appl. Polymer Science, 110. P. 1344 (2008)

22. A. Retolaza, J.I. Eguiazabal, J. Nazabal // Polymer engineering and science, 44. № 8. P. 1405 (2004)

23. S.A. Madbouly, T. Chiba, T. Ougizawa, Inoue T. // Polymer, 42. № 4. P. 1743 (2001)

24. L. D'Orazio, G. Cecchin // Polymer, 42. P. 2675 (2001)

25. A.A. Askadskij, M.N. Popova, V.I. Kondrashchenko, Fiziko-himiya polimernyh materialov i metody ih issledovaniya. Moskva, Izdatel'stvo ASV, 407 c (2015)

26. A.A. Askadskij, E.S. Afanas'ev, T.A. Maceevich, M.N. Popova, O.V. Kovriga, V.I. Kondrashchenko // Vysokomolek. soedin. Ser. A. T. 57. № 6. S. 582-604 (2015)

27. A.A. Askadskij, T.A. Maceevich, M.N. Popova, E.S. Afanas'ev // Doklady Akademii Nauk. T. 462. № 5. S. 558-560 (2015)

28. A. Askadskii, T. Matseevich, Al. Askadskii, P. Moroz, E. Romanova, Structure and Properties of Wood-Polymer Composites, Cambridge Scholars Publishing, Cambridge, $231 \mathrm{pp}$ (2019) 